\title{
Remote sensing reconstruction of long-term and dense water level and storage variations of ungauged river in High Mountain Asia
}

\author{
Jiahui $\mathrm{Xu}^{1}$, Chunqiao Song ${ }^{2}$, Chenyu $\mathrm{Fan}^{1}$, Kai Liu ${ }^{1}$, Tan Chen ${ }^{1}$, Linghong $\mathrm{Ke}^{3}$, Shidong \\ Wang $^{4}$, and Lijuan Song ${ }^{1}$ \\ ${ }^{1}$ Nanjing Institute of Geography and Limnology Chinese Academy of Sciences \\ ${ }^{2}$ Nanjing Institute of Geography and Limnology, Chinese Academy of Sciences \\ ${ }^{3}$ Hohai University \\ ${ }^{4}$ Henan Polytechnic University
}

September 24, 2021

\begin{abstract}
Water level and storage are the most critical components for understanding water cycle changes and mechanisms better. Given the lack of in-situ river level monitoring and consecutive satellite altimetry data in the Yarlung Zangbo River (YZR) in High Mountain Asia (HMA) caused by the harsh environment and complex terrain, obtaining accurate and long-term water characteristic changes is challenging. In this study, we reconstructed the dense time series of the YZR water characteristic changes from 2000 to 2020 . The general idea of this method is to obtain the water area information derived from the Global Land Analysis and Discovery (GLAD) dataset, using the hypsometric curves to fill Hydroweb lacked river water level records from the available river area data, and to reconstruct the virtual stations (VSs) water levels in the YZR. Moreover, by combining area estimates with the changes in water level, the variations of the YZR water storage have been obtained. The obtained YZR water storage variation result was compared with the terrestrial water storage anomaly (TWSA) of Brahmaputra basin from Gravity Recovery and Climate Experiment (GRACE) data to discuss the response relationship. Results indicated that the reconstructed water area applied in the YZR with high quantity accuracy (approximately 82\%) and the reconstructed water levels agreed reasonably well with Hydroweb water levels with an average $\mathrm{R}$ of 0.89 . Furthermore, the densified reconstructed water levels provided critical and accurate information on the long-term monitoring in HMA. The YZR water area, level and storage have apparent significant seasonal fluctuations. The declining amplitude of water levels of VSs expanded from the upstream region to the downstream region. In addition, the change in river water storage only accounts for approximately one tenth of that in the basin. This study sheds new light on bridging the gap in monitoring the long-term water characteristic changes over poorly gauged basins by means of optical imaging in combination with partial altimetry satellite, and can be effectively applied in other large rivers in HMA.
\end{abstract}

\section{Hosted file}

manuscript.docx available at https://authorea.com/users/435043/articles/538339-remotesensing-reconstruction-of-long-term-and-dense-water-level-and-storage-variations-ofungauged-river-in-high-mountain-asia 

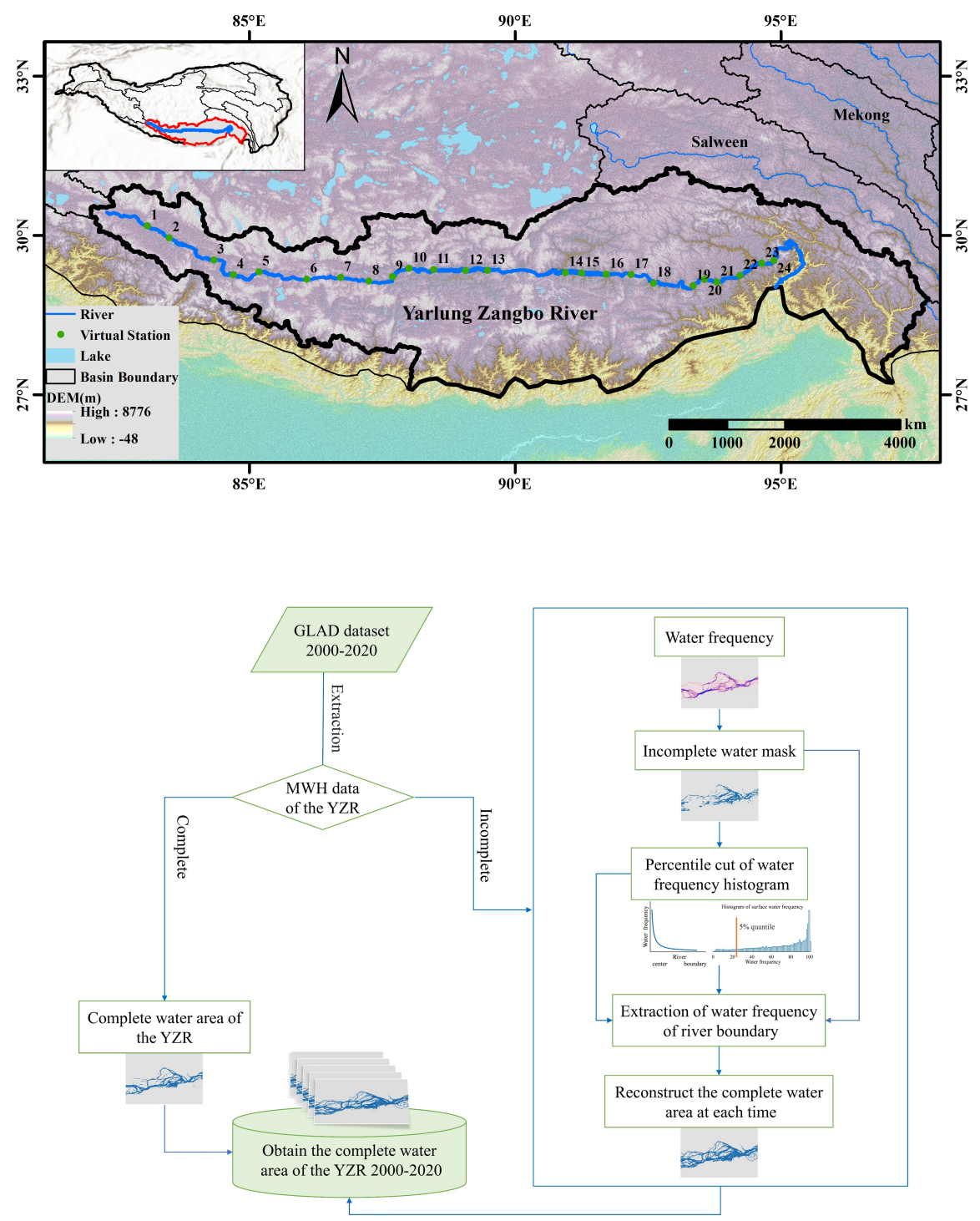

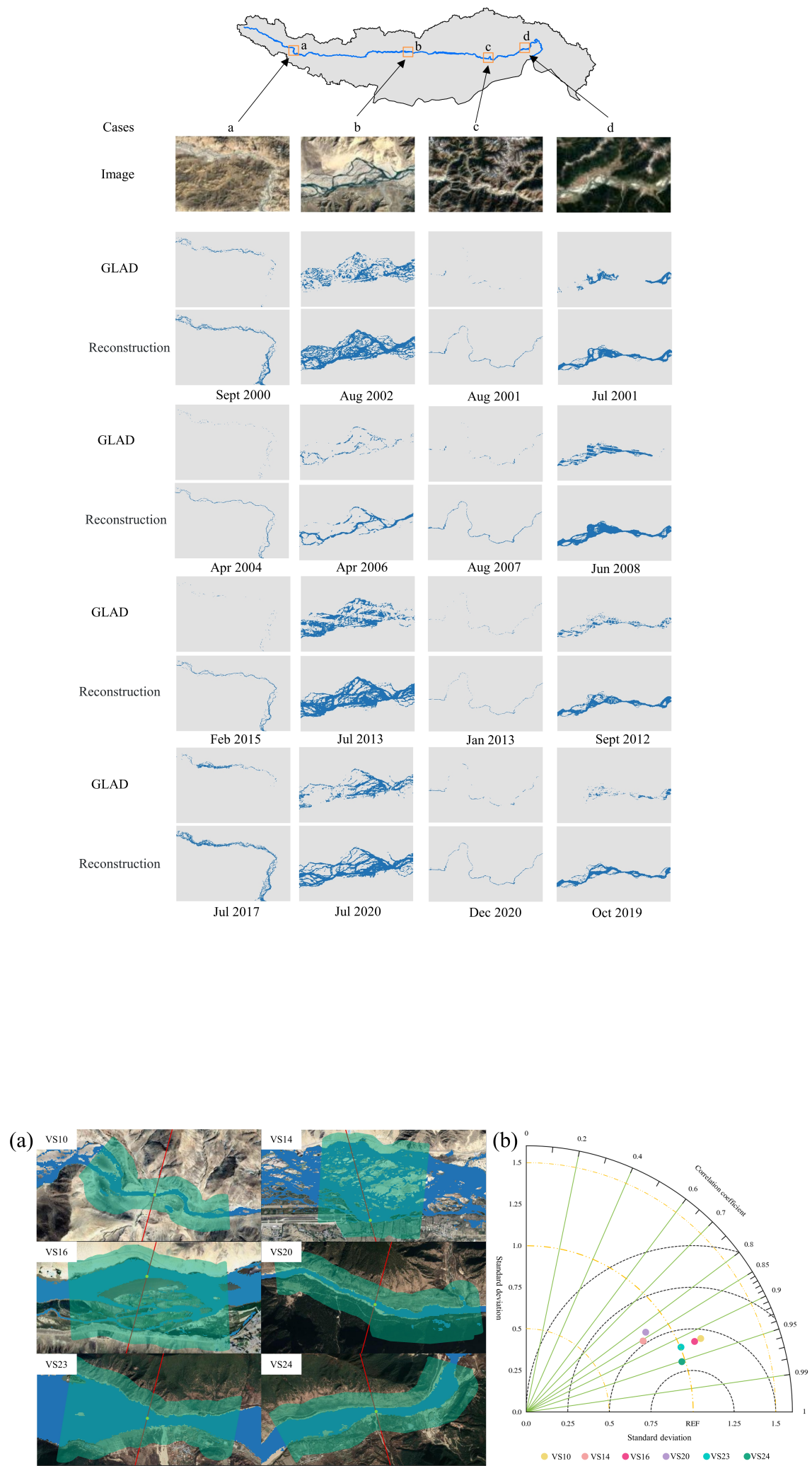

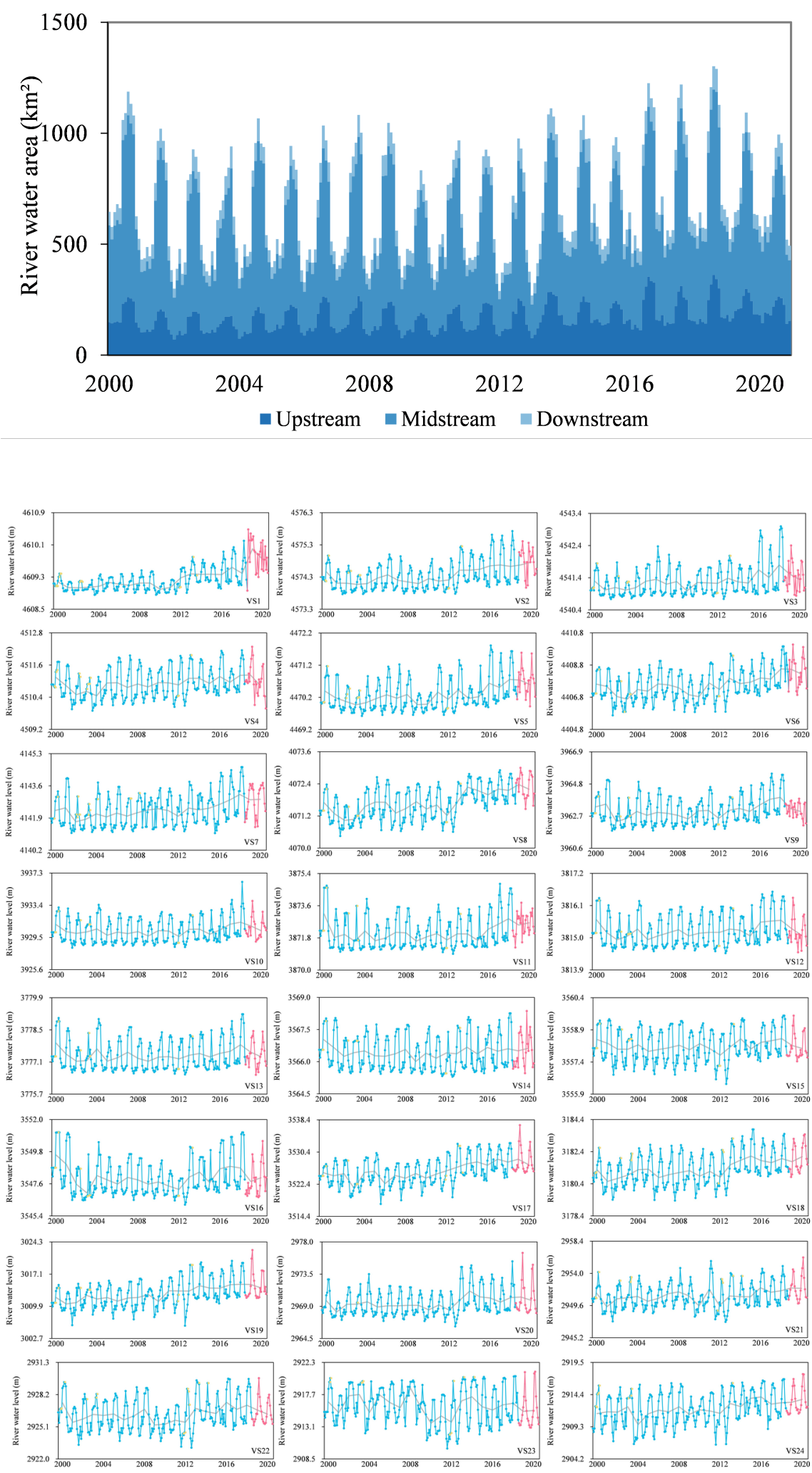

$\rightarrow$ Reconstructed monthly river water level $\rightarrow$ Hydrowweb water level $\rightarrow$ Average level from the months eitherside of the missing data 

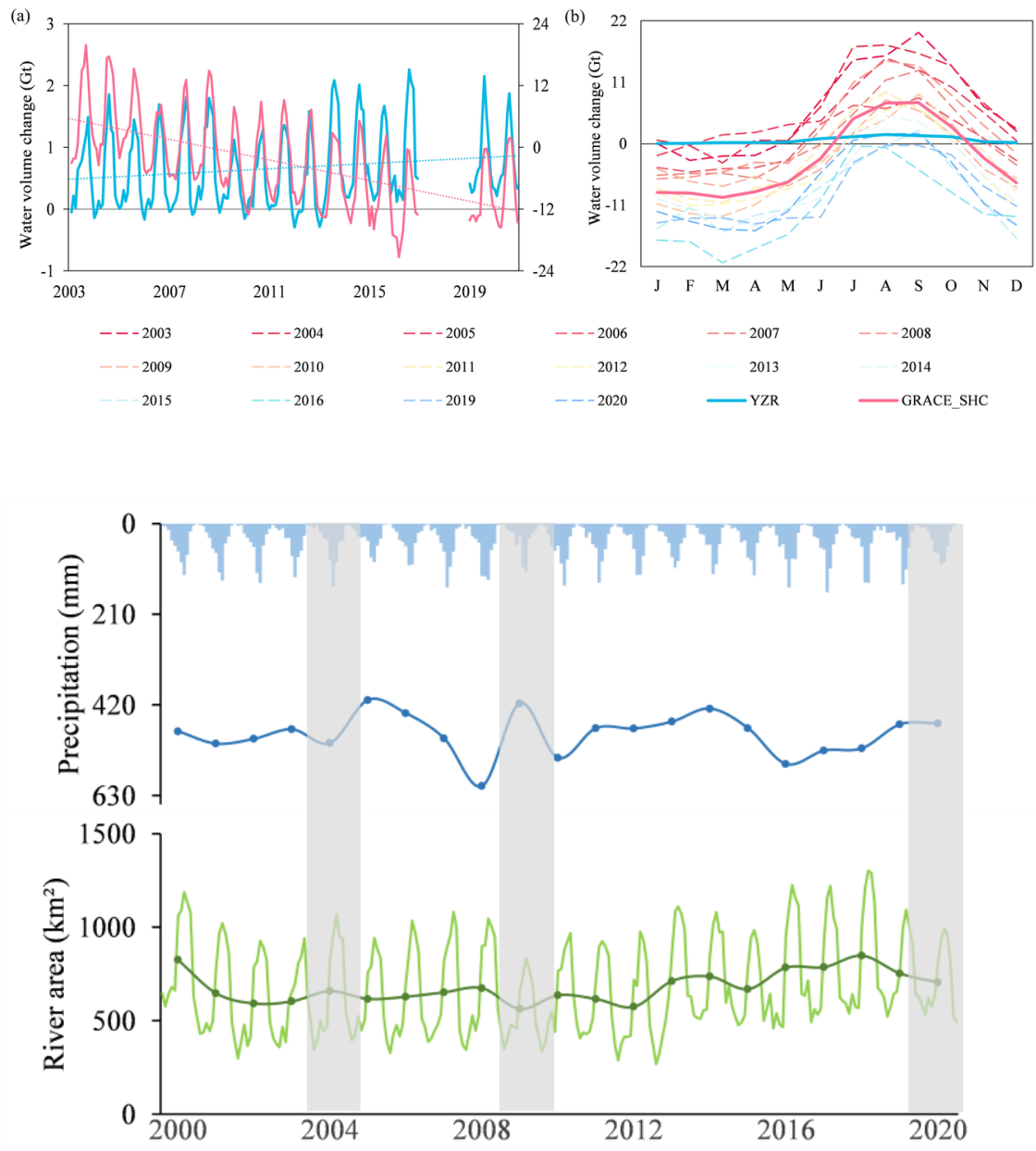

\section{Hosted file}

table1.docx available at https://authorea.com/users/435043/articles/538339-remote-sensingreconstruction-of-long-term-and-dense-water-level-and-storage-variations-of-ungaugedriver-in-high-mountain-asia

\section{Hosted file}

table2.docx available at https://authorea.com/users/435043/articles/538339-remote-sensingreconstruction-of-long-term-and-dense-water-level-and-storage-variations-of-ungaugedriver-in-high-mountain-asia

\section{Hosted file}

table3.docx available at https://authorea.com/users/435043/articles/538339-remote-sensingreconstruction-of-long-term-and-dense-water-level-and-storage-variations-of-ungaugedriver-in-high-mountain-asia 